\title{
L'organització dels textos en els llibres de poesia de Joan Maragall
}

\section{The Organization of Texts in Joan Maragall's Poetry Books}

\author{
IGNASI MORETA \\ Universitat Pompeu Fabra \\ ignasi.moreta@upf.edu \\ Recibido: marzo de 2021. Aceptado: junio de 2021
}

\begin{abstract}
Resum: L'article estudia els elements paratextuals que acompanyen l'obra poètica de Maragall publicada en forma de llibre a fi d'esclarir la manera com l'autor organitza l'arquitectura dels seus llibres. La inclusió dels seus poemes en els llibres de poesia que publica, la seva disposició en l'arquitectura dels llibres, l'organització (seccions, portadelles, recursos tipogràfics emprats, índexs, etc.), les continuïtats i discontinuïtats entre els seus llibres, són elements que ens parlen de com Maragall vol ser llegit. Maragall construeix els seus llibres amb plena consciència $\mathrm{i}$ amb una gran professionalitat, organitzant-los de manera pensada i sofisticada.
\end{abstract}

Mots clau: Maragall, ecdòtica, paratextos, poesia, edició de textos, filologia

\begin{abstract}
The article studies the paratextual elements that accompany Maragall's poetic work published in book form in order to clarify the way in which the author organizes the architecture of his books. The inclusion of his poems in the poetry books that he publishes, their arrangement in the architecture of the books, the organization (sections, covers, typographic resources used, indexes, etc.), the continuities and discontinuities between his books, are elements that tell us about how Maragall wants to be read. Maragall builds his books with full conscience and with great professionalism, organizing them in a thoughtful and sophisticated way.
\end{abstract}

Key words: Maragall, ecdotics, paratexts, poetry, edition of texts, philology

El 25 de març de 1911 Maragall escriu a Unamuno, que li havia manifestat el seu neguit per no disposar dels seus llibres de poesia: «No se apure V. por la pérdida de mis libros. Tengo agotadas las Visions \& Cants, y Enllà, y ahora también Seqüències se está agotando, de modo que pienso hacer pronto una 
edición conjunta de todo ello. Lo tendrá V. todo de nuevo» (Maragall 1961: 944). Maragall va morir el 20 de desembre d'aquell any sense haver arribat a treballar en el projecte anunciat al rector de la universitat de Salamanca nou mesos abans. No sabem què hauria fet Maragall si aquesta reedició de tots els seus llibres de poesia hagués tirat endavant: com hauria organitzat els textos, com els hauria corregit, si hauria suprimit textos o n'hauria afegit de nous... Sabem que, quan l'any 1909 publica l'antologia per a infants Tria (Maragall 1909), va revisar els textos antologats, cosa que Ors (2001: 507) va subratllar emfàticament. No era una revisió tan profunda com, per exemple, la que Carner emprendrà més tard sobre la seva pròpia obra. Maragall es corregeix, però sense arribar pròpiament a reescriure's.

Sigui com sigui, la manera com Maragall difon la seva obra ens parla també d'aquesta obra. La publicació dels textos en revistes i la seva posterior inclusió (o exclusió) en llibres, la disposició dels textos en els llibres, la seva organització (les seccions, les portadelles, els recursos tipogràfics emprats, els índexs, els paratextos de tot tipus que acompanyen els poemes...), les continuïtats i discontinuïtats entre els llibres, tot això són elements que ens parlen sobre com Maragall vol ser llegit.

Els paratextos, un terme encunyat per Gérard Genette (1987), poden ser autorials o editorials, és a dir, responsabilitat de l'autor o de l'editor. Malauradament, coneixem poc la relació entre Maragall i els editors de la seva poesia, perquè no se n'ha conservat gaire correspondència. Però del poc que en sabem es pot deduir que Maragall vetlla a fons, personalment, pels seus llibres, per la pulcritud de les edicions i, fins i tot, per la seva difusió.

Així, quan al setembre de 1892 envia al seu amic Anton Roura el llibre Poesias. Originals y traduccions confegit pels amics com a regal de casament, no s'està d'excusar-se per les errates: «Hi ha algunes errates, vull dir que després no em vingues amb orgues» (Maragall 1960: 1106). Al mateix interlocutor li comenta dos anys més tard, el 31 de gener de 1895, els preparatius del seu primer llibre controlat per ell, Poesies: «Tinc preparat per a imprimir un tomet de les poesies fetes des de primers de l'any 91 fins a l'últim del 94 . Ara veuré preus, paper, impremta, etc.» (Maragall 1960: 1117). Poc després, al febrer de 1895, torna a dir-li: «he entregat a $L^{\prime}$ Avenç el manuscrit perquè m'imprimeixin un tomo de Poesies i ara tractem del paper, forma, etc.» (Maragall 1960: 1117).

Maragall declara en diverses ocasions el criteri restrictiu amb què tria els poemes que inclou en els seus llibres. A Lluís Lluís, per exemple, en comentarli Seqüències el 20 de febrer de 1911, li diu: «Realment per ésser tota la meva obra poètica de cinc anys, és petit: però és que de moments de poesia que jo senti fortament, en tinc pocs; i no vull fixar en vers sinó aquests; i encara quan sóc a fer-ne un llibre pel públic, rebutjo els que no trobo prou vius» (Maragall 1961: 914). La citació és interessant perquè mostra molt clarament que per Maragall tot llibre de poesia és miscel-lani: el que escriu —el que vol «fixar en vers»- són els poemes, i és només posteriorment que es posa a «fer-ne un llibre pel públic» garbellant entre el que ha escrit. 
L'agenda de butxaca de Maragall de l'any 1911 és també un indici del seguiment que fa de la publicació dels seus llibres. El 10 de gener anota el lliurament dels materials del llibre Seqüències a L'Avenç. I els dies 11, 24 i 31 de gener i els dies 1, 3, 7 i 11 de febrer reapareix la referència a L'Avenç a la seva agenda. Sembla, doncs, que tots aquests dies Maragall es va desplaçar a la seu de L'Avenç per controlar els detalls del seu llibre.

Tot apunta, per tant, a una forta implicació de Maragall en l'edició dels seus llibres, una implicació que el duu a responsabilitzar-se no solament de l'aplec dels textos sinó també de la seva organització en els volums.

\section{I.- LA TENSIÓ ENTRE LLIBRE I POEMA}

Maragall va publicar en vida cinc llibres de poesia: Poesies (1895), Visions \& Cants (1900), Les disperses (1904), Enllà (1906) i Seqüències (1911). S'hi ha d'afegir el llibre Poesias (1891), publicat en vida de Maragall però a iniciativa aliena, sense intervenció ni coneixement de l'autor (dels poemes que conté, Maragall n'integrarà sis a Poesies i dos a Les disperses, i en quedarà un sense integrar-se a cap llibre controlat per l'autor); l'autoantologia en vers i en prosa Tria (1909), destinada als infants, que inclou quinze poemes publicats prèviament; la tragèdia en versos decasíllabs Nausica, publicada pòstumament (1913); la poesia difosa en revistes i àlbums però no aplegada en vida; i la poesia dispersa que Maragall va deixar inèdita entre els seus manuscrits.

Els cinc llibres de poesia de Maragall són, tots cinc, aplecs miscel-lanis de textos escrits anteriorment $i$, en molts casos, publicats també anteriorment en publicacions disperses. Ja ho hem assenyalat en comentar la clarificadora citació de la carta a Lluís Lluís del 20 de febrer de 1911 (Maragall 1961: 914). Aquest caràcter miscel-lani ens permet constatar que la unitat realment important en Maragall no és el llibre, sinó la poesia. Només hi ha dos projectes poètics que matisen aquesta realitat: El comte l'Arnau i Nausica. El comte l'Arnau és el nom que podem donar a l'únic intent de poema llarg de Maragall, que publica en tres lliuraments a Visions \& Cants (primera part), Enllà (segona part) i Seqüències (tercera part) i que consta d'un total de 903 versos. Nausica és una tragèdia que consta de 1.662 versos decasílllabs. Tota la resta de la seva producció la constitueixen poesies breus.

Que Maragall publiqui aplecs de poesies i no poemes llargs obeeix sens dubte a les seves posicions estètiques sobre la inspiració, que el porten a concebre el poeta com a transmissor més que com a creador (Moreta: 85-86, 217-219, $228,344,348$ ), a prioritzar el fragmentarisme («això és l'única poesia vera, lo fragmentari», diu Maragall a Alcover el 10 de febrer de 1909, com es recull a Maragall 1960: 927 i comenta Quintana Trias: 341-348), a criticar la tasca d'arrodoniment i allargament pròpia del poema llarg («heu dit paraules sagrades: ¡no les toqueu!», diu al pròleg a la poesia de Francesc Pujols, dins Maragall 1960: 822), etc. La preferència pel fragmentarisme i la brevetat allunyen Maragall de Verdaguer i l'acosten a la modernitat. En una carta a Felip Pedrell 
del 9 de gener de 1900 (Terry: 27), Maragall reflexiona sobre la tensió entre el poema llarg i el recull de poemes:

En mi primera juventud soñé en hacer de la sola figura del «Comte l'Arnau»
un gran poema: y ahora resulta que, aún acompañado de otros hermanos suyos
en leyenda, formará parte el tal poema de un pequeño recueil de poesías. Esta
es la historia de mi «Comte Arnau»... que todavía corre por dentro de mí
como en la leyenda. ¿Haré algo más de él? No lo sé. [...] Morera y Gay (entre
otros) me exigen que convierta mi fantasía fragmentaria en libro, cosa á que
yo no me hé rendido nunca sino condicionalmente, es decir, si el libro se me
aparecía; porque yo puedo lo que puedo, pero no quiero confeccionar.

Maragall no fa poemes llargs sinó recueils de poesia perquè es nega a confeccionar, atès que entén la tasca poètica com la transcripció d'allò que li és donat i no com la construcció voluntariosa i disciplinada d'un projecte literari. I, amb tot, la temptació del poema llarg hi és, com expressa clarament a la primera frase del fragment citat. Una temptació juvenil que es tradueix en una certa recança pel fet que el seu poema El comte l'Arnau es limiti a ser una poesia més dins «un pequeño recueil de poesías». I no renuncia a reconvertir-la en un poema llarg.

El comte l'Arnau com a llibre és una mera hipòtesi que, a més, en cas de publicar-se com a tal en el marc d'una edició de tota la poesia de Maragall, obligaria a repetir versos també inclosos en tres dels cinc llibres de Maragall o a suprimir-los d'aquests llibres. Això últim és el que es va fer a l'edició de la Viuda de les Obres completes (Maragall 1912), al volum Poesies d'Edimar (Maragall 1947) i al volum I de les Obres completes de Selecta (Maragall 1960). En tots tres casos, el poema s'integrava dins la secció «Visions». L'opció editorial de les últimes edicions filològiques de la poesia de Maragall (1986, 1998, 2010a, 2020) ha sigut, en canvi, la de mantenir els tres lliuraments d'El comte l'Arnau als llocs on es van publicar en vida de Maragall. Fora del marc d'edicions de la poesia completa de Maragall, s'han publicat diverses edicions d'El comte l'Arnau en volum independent (entre les últimes, Maragall 1995, 2010b).

La publicació d'El comte l'Arnau com a text seguit i autònom topa amb una primera dificultat de tipus pràctic: ¿quin és el títol del conjunt? Felip Pedrell va ser el primer a detectar el problema i a plantejar-lo obertament a Maragall: «Si la segunda parte de la obra se titula propiamente L'ànima en pena ¿cómo se titulará la primera, dado que el título general de la obra ha de ser El Comte Arnau?» (Terry 1964: 45) Pedrell pressuposa que el títol donat a la primera part és el que ha de servir per a tot el conjunt, i atès que la segona part té un títol propi, considera que cal trobar un títol específic per a la primera. La pressuposició de Pedrell l'han compartit fins avui tots els editors que han publicat el poema conjuntament com a volum independent. Tanmateix, la resposta de Maragall va en una altra direcció (Terry 1964: 46-47):

No se me ocurre de pronto título especial para la primera parte, de modo que en diciendo que la obra es: «El comte l'Arnau» toda ella, quizás no hay necesidad 
de decir que la segunda parte es «l'ànima en pena». Este título lo puse antes de saber la concepción general de V. para publicar en mi próximo tomo de poesías la segunda parte sola, ya que la primera era ya publicada. Pero ahora, en que irán las dos juntas al teatro, ó como se llame, formando un solo poema musical, creo que basta que éste sea todo él «El comte l'Arnau».

L'opció de Maragall l'any 1904, quan ha publicat la primera part i escrit part de la segona, és la d'anomenar tot el conjunt El comte l'Arnau, amb doble article definit: davant de comte i davant d'Arnau. I en lloc d'inventar un títol específic per a la primera part, prefereix suprimir el títol específic de la segona, la funció del qual té sentit si aquesta segona part es publica exempta en un volum poètic de Maragall amb altres textos i sense la primera part, com va ser efectivament el cas a Enllà (on el títol «L'ànima en pena» es va reduir finalment a «L'ànima»). A la correspondència amb Pedrell, Maragall es refereix al seu poema alternant sobretot les formes El comte l'Arnau i Comte l'Arnau, perquè el poeta acostuma a citar els títols a la francesa, és a dir, suprimint-ne l'article inicial (o aglutinant-lo amb la preposició precedent) quan li convé per adaptar-lo al context sintàctic en què l'esmenta. A la carta a Carles Rahola del 23 de gener de 1911 parla també de «una tercera y me sembla que ultima part del Comte l'Arnau». ${ }^{1}$ I a la carta a Joan Pérez Jorba del 14 d'abril de 1911 diu que el seu interlocutor ha aprofundit «en el Comte l'Arnau». A l'Arxiu Joan Maragall es conserven dos manuscrits de «La fi del comte l'Arnau». El més antic es titula: «Tercera part del "Comte l'Arnau"», amb «Comte l'Arnau» entre cometes:

Fig. I: MANUSCRIT DE LA TERCERA PART D'EL COMTE L'ARNAU

(ARXIU JoAn MARAGaLL)

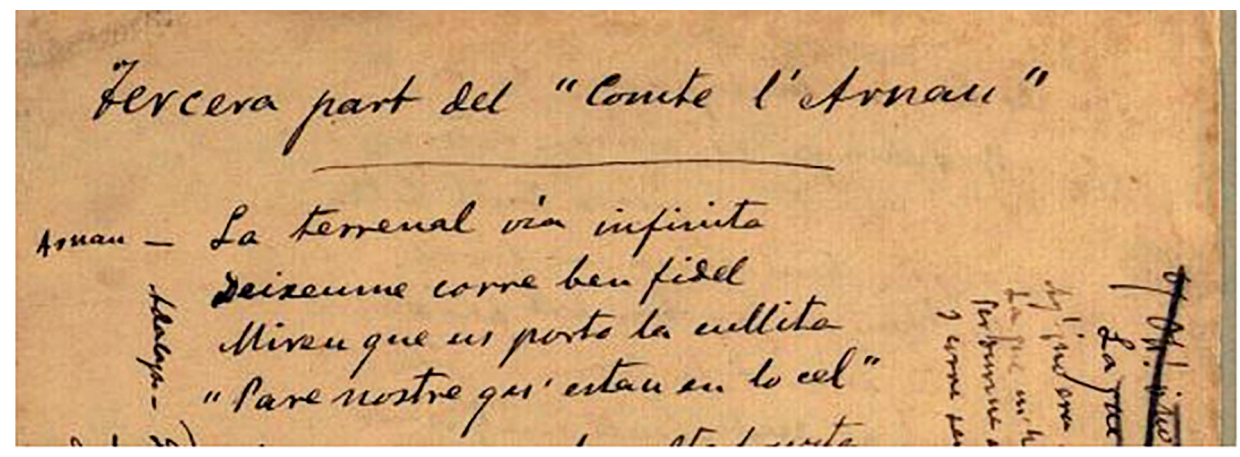

El segon manuscrit conservat és el destinat a la publicació de Seqüències. El full on s'inicia el poema no té títol, però sí que el trobem a la camisa amb funció

${ }^{1}$ Carta a Carles Rahola de 23 de gener de 1911 (mrgll-Mss. 6-49-5/1). Còpia manuscrita no autògrafa, AJM. 
de portadella que contenia aquest manuscrit. Hi podem llegir: «La fi del Comte l'Arnau i Cant espiritual». No posa «Comte l'Arnau» entre cometes, com en el manuscrit primigeni, però la disposició cal-ligràfica fa pensar que «Comte l'Arnau» és no solament una al-lusió al personatge sinó també al poema, i que, per tant, «La fi» és un títol al mateix temps temàtic i remàtic: és la fi del personatge d'Arnau, però és també la fi del poema El comte l'Arnau:

Fig. 2: Portadella del manusCrit de la tercera PART D'El COMte L'ARNAU (ARXIU JoAN MARAGALL)

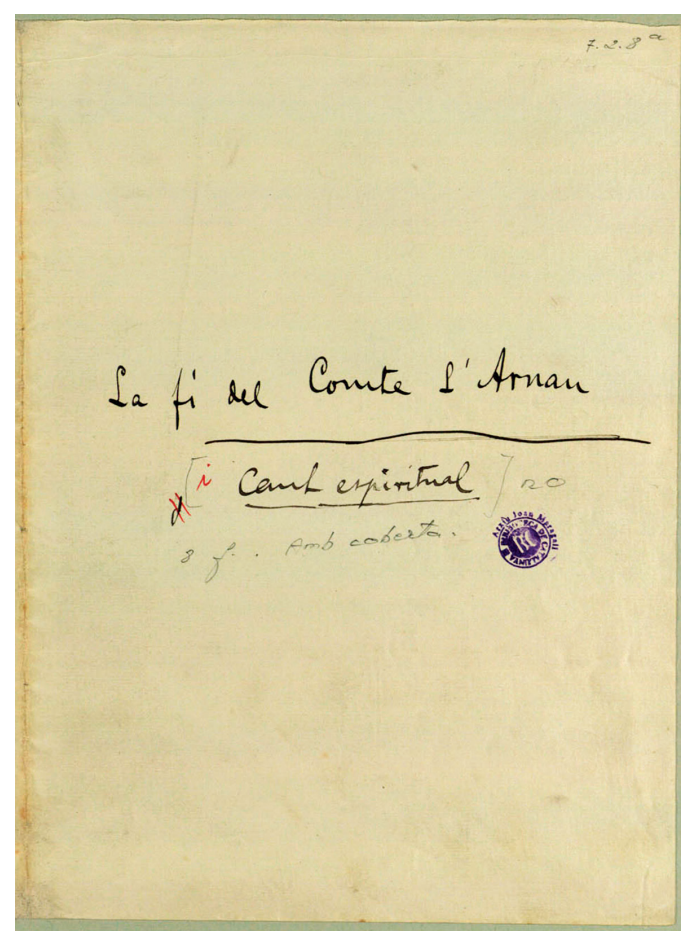

Per tots aquests motius, en cas de publicació independent i seguida de les tres parts del poema, el títol que cal donar al conjunt és, des del meu punt de vista i d'acord amb el que es desprèn de l'epistolari de Maragall i dels manuscrits conservats, El comte l'Arnau.

\section{II.- TÍTOL I SUBTÍTOL DELS LLIBRES DE POESIA: FUNCIÓ REMÀTICA I FUNCIÓ TEMÀTICA}

Els cinc llibres de poesia de Maragall tenen, en el títol o en el subtítol, una indicació remàtica (Genette 1987: 82-83), és a dir, una al-lusió al gènere del 
llibre. Maragall (o els seus editors) es veu obligat a deixar clar, a la portada del llibre, que el que hi trobarà el lector és poesia. En els dos primers llibres aquesta declaració s'ofereix en el títol mateix, que és clarament remàtic: Poesies i Visions \& Cants. Tots dos títols expressen clarament que el que el llibre ofereix és poesia. Dels altres tres llibres, dos són també remàtics però de manera menys transparent, cosa que explica que en tots tres casos aparegui un subtítol amb una funció específicament remàtica: Poesies originals i traduccions de Goethe en el cas de Les disperses i Poesies en el cas d'Enllà i Seqüències.

El caràcter remàtic del títol Les disperses es fa evident quan es llegeix el subtítol: són Poesies originals i traduccions de Goethe. Es tracta, per tant, d'un procediment catafòric: primer se'ns descriu com són (Les disperses) i després se'ns ofereix el subjecte descrit (Poesies originals i traduccions). El pròleg «Als amics de Joventut» que encapçala el volum (Maragall 2020: 89-90) confirma, per si en quedés cap dubte, aquesta lectura.

Pel que fa al títol Seqüències, és també remàtic, tal com es desprèn del que explica a Carles Rahola el 23 de gener de 1911: l'ha titulat així «perquè gairebé tots [els versos] són seguits d'inspiracions anteriors, especialment una tercera $\mathrm{i}$ em sembla que última part del Comte l'Arnau». ${ }^{2}$ Els poemes són, doncs, seqüències en la mesura que segueixen, donen continuïtat, a «inspiracions anteriors». Seqüències és, en l'ideolecte de Maragall, un sinònim de represes o continuacions: al-ludeix a la forma literària del que conté el llibre i no al tema que hi tracta. ${ }^{3}$

Per tot plegat, Enllà és l'únic títol temàtic dels cinc de Maragall: és l'únic que fa al-lusió - encara que sigui amb la vaguetat pròpia de l'adverbi- a allò de què parlen els poemes. I potser per això ha sigut definit com el títol més maragallià dels cinc (Glòria Casals dins Maragall 1998: 591).

\section{III.- CRITERI CRONOLÒGIC I CRITERI TEMÀTIC EN LA CONFECCIÓ DELS LLIBRES}

A l'hora d'aplegar la seva poesia en reculls miscel-lanis, se sobreposen criteris cronològics i criteris temàtics. Cap dels cinc llibres no s'articula al voltant d'un únic tema - la preferència pels títols remàtics n'és una prova_-, però sí que tots tenen uns eixos temàtics o formals que els cohesionen més enllà de la mera cronologia. Això es desprèn clarament de la selecció dels textos, de la seva organització en seccions i de les mateixes declaracions de Maragall sobre l'organització dels seus llibres. Potser el lloc on Maragall és més explícit és al pròleg de Les disperses, adreçat «Als amics de Joventut»:

\footnotetext{
2 Carta a Carles Rahola de 23 de gener de 1911 (mrgll-Mss. 6-49-5/1). Còpia manuscrita no autògrafa, AJM.

3 Glòria Casals, a Maragall (1998: 720), planteja la hipòtesi d'un guiny que el disseny de la coberta faria al llenguatge cinematogràfic, de manera que el títol seria també una al-lusió al cinema; també Abrams: 231 ha defensat el sentit cinematogràfic del títol; la hipòtesi em sembla, però, indemostrable, i no l'avalen ni la declaració a Rahola ni el contingut del llibre.
} 
Quan me vàreu demanar una col-lecció de poesies pel fulletí de la vostra revista, no tenint-ne jo prous d'aplegades per a fer un volum regular després de l'últim de Visions \& Cants publicat fa tres anys, me féreu venir la temptació de reunir totes aquelles que, no havent escaigut a la mena d'unitat que m'ha plagut donar a mes col-leccions anteriors i que desitjo per la futura, han restat deslligades i disperses publicades per 'quí i per 'llà o no publicades. (Maragall 2020: 89)

Maragall busca, doncs, una «mena d'unitat» per a cadascuna de «mes col-leccions». No es tracta d'aplegar textos simplement, sinó de fer-ho amb sentit. Però amb el benentès, això sí, que es tracta d'aplecs, de «col-leccions» de textos escrits prèviament. El que Maragall escriu, hi insisteixo un cop més, són poemes. Els llibres es confeccionen posteriorment.

Només a la coberta de l'últim dels reculls, Seqüències, Maragall declara explícitament l'abast cronològic del volum, amb la indicació «1906 : 1910» (Glòria Casals, a Maragall 1998: 721, assenyala que la indicació no és exacta, perquè hi ha com a mínim dos textos de 1905). Al pròleg de Les disperses fa explícit que el llibre recull reflexos de la seva vida dels vint als quaranta anys. Als altres tres reculls la cronologia no es declara en termes tan explícits, però la progressió cronològica de la secció CLAROR de Poesies és evidentíssima, molts dels poemes de les seccions InTERMEZzo i CANTs de Visions \& Cants estan datats al peu, els poemes de Les disperses els llegiríem amb la datació al peu si la impremta de Joventut no hagués extraviat aquestes dates en el procés de confecció del llibre (Maragall 2020: 471-472), i alguns dels poemes d'Enllà també estan datats, sigui en el títol («Els ametllers. Fulls de dietari. 1901») o en fet mateix que un poema faci referència a un fet concret («En la tomba nova de Verdaguer»). En molts poemes de Maragall hi ha, doncs, un lligam estret entre el text i la circumstància històrica que el propicia, un lligam que Maragall no solament no pretén mai amagar, sinó que tendeix a explicitar. Això és coherent, un cop més, amb la seva poètica, que s'allunya de la creació en termes d'elaboració d'un artefacte literari i que postula, en canvi, el trasllat al paper de «reflexes de tants moments la meva vida» (Maragall 2020: 89).

Des del punt de vista cronològic, l'organització dels poemes en els cinc llibres de Maragall és la següent:

\section{Poesies}

Data de publicació: 1895

Textos de datació segura entre 1888 («Oda infinita») i 1894 («Goigs a la Verge de Núria»).

\section{Visions \& Cants}

Data de publicació: 1900

Textos de datació segura entre 1892 («La sardana») i 1900 («Cant del retorn»)

\section{Les disperses}

Data de publicació: 1904

Textos de datació segura entre 1881 («Dins sa cambra») i 1903 («Els núvols de Nadal») 


\section{Enllà}

Data de publicació: 1906

Textos de datació probable entre 1901 («Els ametllers») i 1905 («Escòlium»)

Seqüiències

Data de publicació: 1911

Textos de datació segura entre 1905 («La sirena») i 1910 («El pi d'Estrac»)

Les disperses és l'únic recull que aplega textos corresponents a una etapa àmplia, inclosa la joventut de l'escriptor. Es l'únic llibre poètic que Maragall prepara per encàrrec, $i$ això en fa una obra singular on recupera textos antics (el títol, de fet, ja ho declara) sense renunciar, però, a incorporar-hi algunes de les seves últimes creacions poètiques.

Sobre aquest criteri cronològic se sobreposa un criteri temàtic, que explica que poemes que per cronologia haurien pogut ser publicats en un llibre en concret no apareguin fins al llibre següent. Podria ser el cas de «La sardana», que tot i ser anterior a la publicació de Poesies no apareixerà fins a Visions \& Cants, on encaixa perfectament per motius temàtics.

\section{IV.- L'ORGANITZACIÓ INTERNA DELS LLIBRES}

Els grans eixos temàtics de cada llibre es posen de manifest en la manera com Maragall agrupa els poemes en seccions. A Les disperses no hi ha seccions (fora de la distinció, amb la corresponent portadella, entre poesies originals i traduccions de Goethe). A la resta de llibres, sí. Però els llibres no sempre són del tot coherents en l'ús de les portadelles, en la jerarquització dels títols en els seus diversos nivells... Si mirem de posar-hi ordre, hem de tenir presents els següents nivells de jerarquització dels textos:

\section{Llibre \\ 2 Secció de llibre \\ 3 Grup de poemes \\ 4 Poema \\ 5 Secció de poema}

Hem parlat ja de la unitat llibre i la seva contraposició a la unitat poema. Molt més complexa és la delimitació entre secció de llibre, grup de poemes, poema i secció de poema. Dono a l'annex la taula de continguts de cada un dels cinc llibres, amb el títol de llibre en cursiva, el títol de secció de llibre en versaletes, el títol de grup de poemes subratllat, el títol de poema entre cometes, i el títol de seccions de poemes en rodona i sense afegir-hi cap marca tipogràfica específica. En el cas de Les disperses, ometo les traduccions de Goethe i dono l'ordre dels poemes d'acord amb la proposta de restitució de l'ordre formulada per Glòria Casals a Maragall (1998: 406-409). 
De l'estudi atent d'aquesta taula de continguts podem extreure algunes primeres conclusions sobre l'organització dels textos poètics en els cinc llibres de poesia de Maragall:

1. Les disperses és l'únic dels cinc llibres poètics de Maragall que presenta els poemes seguits sense cap mena d'organització interna fora de l'ordre aproximadament cronològic. No hi ha ni seccions ni grups de poemes. El llibre es presenta dividit en dues parts: «Les disperses» -que conté les poesies originals de Maragall— i «Traduccions de Goethe», totes dues amb la corresponent portadella interna. La hipòtesi de Glòria Casals (dins Maragall 1998: 405) és que, tractant-se d'un llibre d'encàrrec, Maragall s'ha d'adaptar a criteris aliens sobre l'extensió del volum, i recorre a textos antics i a traduccions de Goethe per sortir del pas i assolir les dimensions desitjades per l'editor (Abrams: 227-232 discrepa d'aquesta lectura i posa en relleu els paral-lelismes existents entre els textos originals de Maragall i les traduccions de Goethe que inclou el volum). En la seva configuració com a llibre, Les disperses és el volum menys maragallià de tots. Tanmateix, Glòria Casals (dins Maragall 1908: 408) observa «un agrupament temàtic com a principi ordenador dels poemes»:

I amor (a la dona, als amics o el concepte abstracte)

II muntanyes

III pas de l'any

IV «intermezzo», amb clar predomini de la rondalla i de l'element medievalitzant

Des d'aquesta òptica, tindríem, doncs, que fins i tot Les disperses seria un llibre construït amb una clara arquitectura temàtica, amb els poemes organitzats amb quatre seccions, amb la particularitat que aquestes agrupacions no estan explicitades per cap paratext.

2. Poesies i Visions \& Cants són els llibres que tenen una organització més diàfana. En el primer cas, hi ha un poema que fa de pròleg i un d'epíleg, $\mathrm{i}$ entremig hi ha tres seccions (CLAROR, PIRENENQUES i TRÍPTIC DE L'ANY) integrades per diversos poemes, alguns dels quals tenen subseccions. En el segon hi ha tres seccions (VISIONS, INTERMEZzo i CANTS) integrades per diversos poemes, també formats, en alguns casos, per diverses seccions de poema. Ni a Poesies ni a Visions \& Cants no hi ha poemes fora de secció. Les seccions de tots dos llibres s'articulen dins de cadascun d'ells amb simetria: a Poesies, hi ha dues seccions d'obertura i tancament (PRÒLEG i EPÍLEG) i tres entremig (CLAROR, PIRENENQUES i TRÍPTIC DE L'ANY); a Visions \& Cants hi ha dues seccions que constitueixen els dos pols del llibre (VISIONS i CANTS), corresponents als dos substantius del títol del llibre, i una secció de transició entre totes dues (INTERMEZZO) corresponent, si es vol, a la conjunció del títol del llibre. Cal assenyalar, a més, que el recurs tipogràfic a la cursiva per als poemes de l'INTERMEZZo reforça la simetria de les seccions visions i CANTS. Per tots aquests motius, Poesies i Visions \& Cants són clarament els dos 1libres més ben estructurats de l'obra poètica de Maragall. 
3. Enllà és, en coherència amb la vaguetat del títol, el llibre de Maragall que té una organització més confusa i acumulativa, sense cap mena de simetria, amb vuit poemes fora de secció i dos més («L'ànima» $\mathrm{i}$ «Escòlium») integrats en l'única secció diferenciada del llibre, que té per títol el mateix del primer poema: L'ÀnIMA. D'entre els poemes fora de secció, n'hi ha quatre («Les muntanyes», «Retorn», «Represa» i «Glosa») que es presenten en forma de grup de poemes, grup titulat Les muntanyes. Considero Les muntanyes un grup de poemes i L'ÀNIMA una secció per la manera com el volum jerarquitza les parts: L'ÀNIMA té portadella pròpia (és l'única portadella interna de tot el volum), i el títol apareix, doncs, dos cops: a la portadella per indicar el nom de la secció i encapçalant el poema per indicar el títol del poema. A l'índex del volum Enllà, L'Avenç (o Maragall, perquè no sabem si aquest tipus de decisions les prenia l'autor o l'editor) va optar per no repetir el títol (com a títol de secció i com a títol de poema hauria hagut de figurar dues vegades, amb un tractament tipogràfic diferenciat), de la mateixa manera que, en el cas del grup de poemes Les muntanyes, no va repetir el títol tot i que conceptualment hauria calgut fer-ho: d'una banda, com a títol comú a tot el grup de poemes, i de l'altra, com a títol específic del poema «Les muntanyes». Hi tornarem en l'apartat VI.

4. A Seqüències, sembla com si L'Avenç o Maragall haguessin volgut esmenar la confusió de l'índex d'Enllà, perquè el volum torna a integrar tots els poemes en seccions, com a Poesies i a Visions \& Cants. Quan una secció té un sol poema, el títol es repeteix dos cops, tant en el cos del llibre (títol a la portadella interna i títol encapçalant el text) com a l'índex, que és el que Enllà no feia. Som lluny, tanmateix, de la diàfana organització de Poesies i Visions \& Cants, pels motius següents: $a$. a Seqüències no hi ha simetria entre seccions; $b$. a Seqüències una de les seccions és constituïda per un sol poema (ODA NOVA A BARCELONA), cosa que en certa manera desvirtua el sentit mateix del que és secció, i $c$. a Seqüències dues de les seccions són explícitament una mera juxtaposició de poemes, cosa que també les desvirtua en alguna mesura. Pel que fa a la manera d'organitzar els textos i de titular el llibre i les seccions que l'integren, Sequiències és un llibre molt singular, perquè tant el títol del llibre com el de les quatre seccions fan explícit el joc de represes de temes anteriors que proposa el volum. Ja hem vist que Seqüències és un títol remàtic: els poemes són seqüències en la mesura que segueixen, donen continuïtat, a «inspiracions anteriors», com diu a la carta a Rahola citada més amunt. I per això totes les seccions expliciten aquesta continuïtat: SEGUIT DE LES VISTES AL MAR, REPRESA D'HAIDÉ I ALTRES, ODA NOVA A BARCELONA i LA FI DEL COMTE L'ARNAU I CANT ESPIRITUAL. En el primer cas, el terme clau és seguit; en el segon, represa; en el tercer, oda nova (ho podem entendre com a represa del gènere de l'oda, conreat per Maragall a l'«Oda infinita» de Poesies i a l'«Oda a Espanya» de Visions \& Cants i, també, com a renovació de l'«Oda a Barcelona» de Verdaguer); en el quart, la fi. En tots quatre casos, el terme remàtic (seguit, represa... i altres, oda nova i la fi) acompanya el temàtic: les 
vistes al mar, Haidé, Barcelona i Comte l'Arnau. En aquest marc, «Cant espiritual» és el que Genette (1987: 92) anomena un «títol mixt» perquè és tant remàtic («Cant») com temàtic («espiritual»), i apareix juxtaposat a «La fi del comte l'Arnau» de la mateixa manera que els poemes «altres» es juxtaposen a «Represa d'Haidé».

\section{V.- LA DISTINCIÓ ENTRE GRUP DE POEMES NUMERATS I POEMA SERIAT}

La distinció entre grup de poemes numerats i poema seriat no és evident, $\mathrm{i}$ constitueix el trencacolls més important a l'hora de mirar d'entendre l'organització dels textos en els llibres de Maragall.

Entenc per grup de poemes numerats els conjunts de poemes precedits per una xifra romana consecutiva que constitueixen un grup diferenciat a l'inici d'una secció. Entenc per poema seriat els poemes unitaris amb títol propi i seccions numerades.

En els llibres de Maragall, són grups de poemes numerats els set poemes inicials de la secció PIRENENQUes (Poesies) i els set poemes inicials de la secció SEGUIT DE LES VISTES AL MAR (Seqüències). En tots dos casos, són poemes que es presenten sense títol propi (ni de cada poema ni del conjunt), van numerats en xifres romanes, se situen a l'inici d'una secció que conté també altres poemes amb títol propi i sense numeració, i figuren a la taula de continguts del llibre identificats amb la numeració $\mathrm{i}$ el primer vers, tal com veiem a les figures 3 i 4 .

Evidentment, són poemes que estan vinculats entre ells, cosa que la publicació conjunta seguida (sense començar cada poema en pàgina nova) i la numeració correlativa que els encapçala reforcen clarament. Però són també poemes independents que admeten perfectament, cadascun d'ells, una lectura autònoma.

En canvi, «Festeig vora la mar Cantàbrica» (Poesies) és un poema seriat, és a dir, un poema amb cinc seccions numerades. És, en qualsevol cas, un sol poema tot ell, un poema que podem llegir com el reportatge poètic d'una estada molt ben documentada de Maragall a la platja de Las Arenas, a Getxo (Biscaia), durant l'agost de 1891, per festejar amb Clara Noble Malvido, amb qui es casarà al final d'aquell mateix any (Moreta: 473); tot el poema respon, doncs, a una mateixa experiència vital clarament fixada en l'espai i en el temps.

Dins Poesies, hi ha altres poemes seriats, a més de «Festeig vora la mar Cantàbrica». De fet, tots els de la secció TRÍPTIC DE L'ANY ho són: «Quaresma» consta de cinc seccions numerades, «Corpus» de quatre numerades (una d'elles, a més, amb títol propi), i «Nadal» consta de set seccions sense numeració ni títol de cap mena. 
Fig. 3: Taula del llibre Poesies ( 895 )

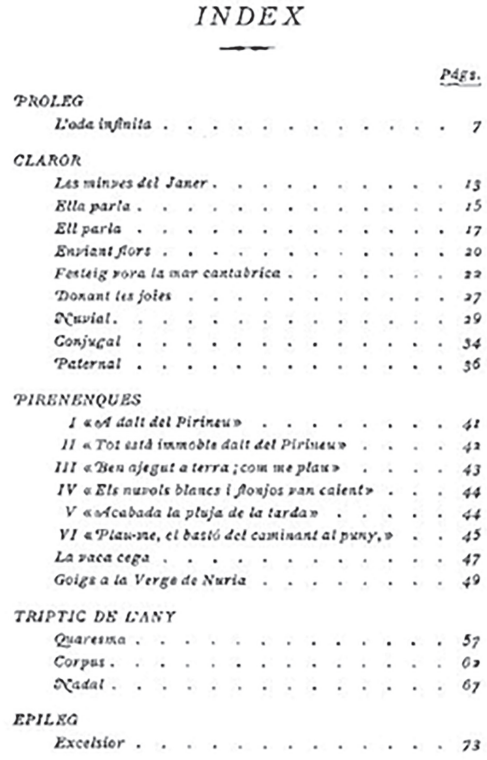

Fig. 4: TAula del Llibre SEQÜÈNCIES (I9I I)

\section{$T A \cup L A$}

Seguit de les visles al mar

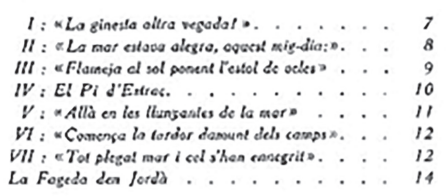

Represa de Haydé $i$ allies

Represa de Hasdi. . . . . . . . . . . . 17

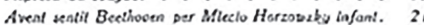
La Sitena (frognenl) . . . . . . . . 23 Primer dol. . . . . . . . . . . . . . 25

En ena cose ness.

Fl dony. . . . . . . . . . . 28

Oda nova a Barcelona

Oda nosa a Barcelono........... . 31

La Fi del Comle l'Arnau

$i$ Cant Espirilual

La FI del Comle CArnou . . . . . . . . . 39 Ceal Espiriluol. . . . . . . . . . . . . 19 
Una dificultat en aquesta distinció entre grups de poemes numerats i poemes seriats el constitueix el tractament diferenciat que ens obliga a fer de les «Vistes al mar» (Enllà) i dels set poemes inicials de la secció SEGUIT DE LES VISTES AL MAR (Seqüències). Les «Vistes al mar» són un poema seriat amb cinc seccions al seu interior, mentre que els set poemes inicials de SEGUIT DE LES VISTES AL MAR constitueixen un grup de poemes numerats. ¿Per què en el primer cas parlem d'un sol poema amb subdivisions numerades i, en el segon, de grup de poemes numerats?

Tenim, en primer lloc, la informació que ens donen els elements tipogràfics: en l'índex d'Enllà les «Vistes al mar» apareixen sense cap més indicació, és a dir, sense especificar el primer vers de cadascuna de les cinc unitats que les componen; en canvi, l'índex de Seqüències sí que ofereix el detall de cadascuna de les unitats numerades de SEGUIT DE LES VISTES AL MAR. Es podria objectar, però, que són llibres diferents, fets amb criteris tipogràficoeditorials diferents, i que inferir-ne un estatut diferenciat de les parts que constitueixen els conjunts en un i altre recull és abusiu. I s'hi podria afegir que resulta estrany que les «Vistes al mar» les considerem un sol poema i els poemes de SEGUIT DE LES VISTES AL MAR els considerem un conjunt de poemes diferents, quan és evident que l'expressió seguit de fa explícita la relació de continuïtat entre els dos conjunts (després hi tornarem). Tanmateix, crec que la lectura de «Vistes al mar» $\mathrm{i}$ dels poemes inicials de SEGUIT DE LES VISTES AL MAR avala aquest tractament diferenciat. Fixem-nos amb la segona unitat de «Vistes al mar»: «Degué ser un dia així que el bon Jesús». Aquest vers només s'entén després d'haver llegit la primera unitat, on se'ns parla del que succeeix un dia concret en què floreixen la pomera i el presseguer. En aquest sentit, «un dia així» actua com una estructura anafòrica que té el seu antecedent en els fets reportats en la unitat anterior. La segona unitat de «Vistes al mar» no admet, doncs, una lectura autònoma. La mètrica és també un element clarament cohesionador del conjunt: les «Vistes al mar» es construeixen en decasíllabs no cesurats (unitats I, II i V, en aquest últim cas en combinació amb un hexasílllab), en pentasílllabs (unitat III, on els podem llegir com si fossin hemistiquis de decasíl·labs cesurats) i en pentasíllabs combinats amb decasílllabs cesurats a la mitjana (unitat IV). Ens movem, doncs, entre els pentasílllabs, els decasílllabs cesurats a la mitjana (on es juxtaposen hemistiquis de cinc sílllabes) i els decasíl-labs no cesurats. Oscilem sempre entre el cinc i el deu.

En canvi, als poemes inicials de SEGUIT DE LES VISTES AL MAR la lectura no afavoreix la consideració del conjunt com un sol poema. No hi ha elements cohesionadors tan marcats com a «Vistes al mar»: «La ginesta altra vegada...» té molt poc a veure amb «El pi d'Estrac». La mètrica és també molt més diversa: heptasíl.labs («La ginesta altra vegada...»), decasílllabs («La mar estava alegre, aquest migdia...», «Flameja al sol ponent l'estol de veles», «Allà en les llunyanies de la mar...»), alexandrins («El pi d'Estrac») i combinació de metres diferents de nombre parell de síl·labes («Comença la tardor damunt dels camps...» $\mathrm{i}$ «Tot plegat mar i cel s'han ennegrit...»). 
Malgrat, doncs, que els poemes numerats de SEGUIT DE LES VISTES AL MAR donen continuïtat a les «Vistes al mar», hem de considerar que «Vistes al mar» constitueix un sol poema seriat, mentre que SEGUIT DE LES VISTES AL MAR és una secció de llibre que consta d'un grup de poemes numerats més el poema «La fageda d'en Jordà».

També cal assenyalar que no tot poema amb subdivisions numerades és pròpiament un poema seriat. «Festeig vora la mar Cantàbrica» (Poesies), els poemes de TRÍPTIC DE L'ANY (Poesies), «Davant del temporal» (Les disperses) i les «Vistes al mar» (Enllà) són els exemples més clars de poesia seriada en l'obra de Maragall. Són poemes seriats perquè són una juxtaposició de fragments no definida: si se'n suprimís algun o se n'hi afegís algun altre, la sèrie no se'n ressentiria. Les quatre subdivisions numerades de «Joan Garí», les deu de «El comte Arnau» i les cinc de «L'estimada de don Jaume» (tots tres poemes són de Visions \& Cants), les cinc de «Diades d'amor» (Les disperses) i les cinc de «Retorn» i les set d' «Ànima» (tots dos poemes són d'Enllà), constitueixen no pas unitats d'una sèrie, sinó «capítols» o «episodis» de poemes en gran mesura narratius. Tradicionalment, s'han anomenat seccions, una terminologia que crec que cal mantenir. «La sardana» també té quatre parts numerades, però no és cap poema seriat ni cap poema narratiu dividit en episodis: és senzillament un poema estructurat en quatre estrofes de versificació idèntica, estrofes que l'autor ha numerat — sense que aquest últim fet converteixi el poema en un poema seriat.

\section{VI.- ELS GRUPS DE POEMES NO NUMERATS}

Hem parlat dels grups de poemes numerats a l'inici de secció, cohesionats entre ells per la numeració correlativa i per la disposició a l'inici d'una secció que els dona títol, encara que les edicions només l'explicitin com a títol de secció i calgui sobreentendre'l com a títol també del grup de poemes numerats. Però hi ha encara una segona modalitat de grup de poemes: els conjunts de poemes que Maragall associa explícitament amb un títol comú que no és títol de secció i que no aplega poemes numerats sinó titulats. En els llibres de poesia de Maragall això succeeix en dos casos: amb Els tres cants de la guerra, dins Visions \& Cants, i amb Les muntanyes, dins Enllà.

En el cos del llibre Visions \& Cants, el títol Els tres cants de la guerra, que aplega «Els adeus», «Oda a Espanya» $\mathrm{i}$ «Cant de retorn», té un tractament tipogràfic únic. És a dir, podríem dir que tipogràficament és un hàpax: l'estil amb què apareix la indicació Els tres cants de la guerra no es repeteix en tot el llibre; és un títol afegit sobre el primer dels poemes que aplega, «Els adeus». Tècnicament, és el que s'anomena un sobretítol. En l'índex del volum, els títols dels tres poemes d'Els tres cants de la guerra apareixen amb el mateix estil tipogràfic que la resta de títols de poemes del volum, i simplement van precedits de la indicació Els tres cants de la guerra també amb un tractament tipogràfic únic dins l'índex. Vegem-ho: 
FIG. 5: Sobretítol «ElS TRES CANTS DE LA GUERRA» I POEMA «ELS ADEUS» DINS VISIONS \& CANTS (I9O0)

\author{
ELS TRES CANTS DE LA GUERRA
}

\author{
ELS ADÉUS
}

Que senyals d'adéu han fet mans exteses cap al mar,

vers els barcos que fugien am les cobertes massa carregades, cap allà on les onades llüen retorcent-se i bramant assoleiades

Quants adéus desde aquell adéu primer, quan Cal, havent fet la mort, menjả al vespre un bocí a l'endiablada, el bastó al puny, cenyida la cintura, voltat de plors de nins, i la muller, que li deia am lament: "No vagis pas cap a Ponent!»

Figs. 6 i 7: TAUla DEL Llibre Visions \& CANTS ( I900)
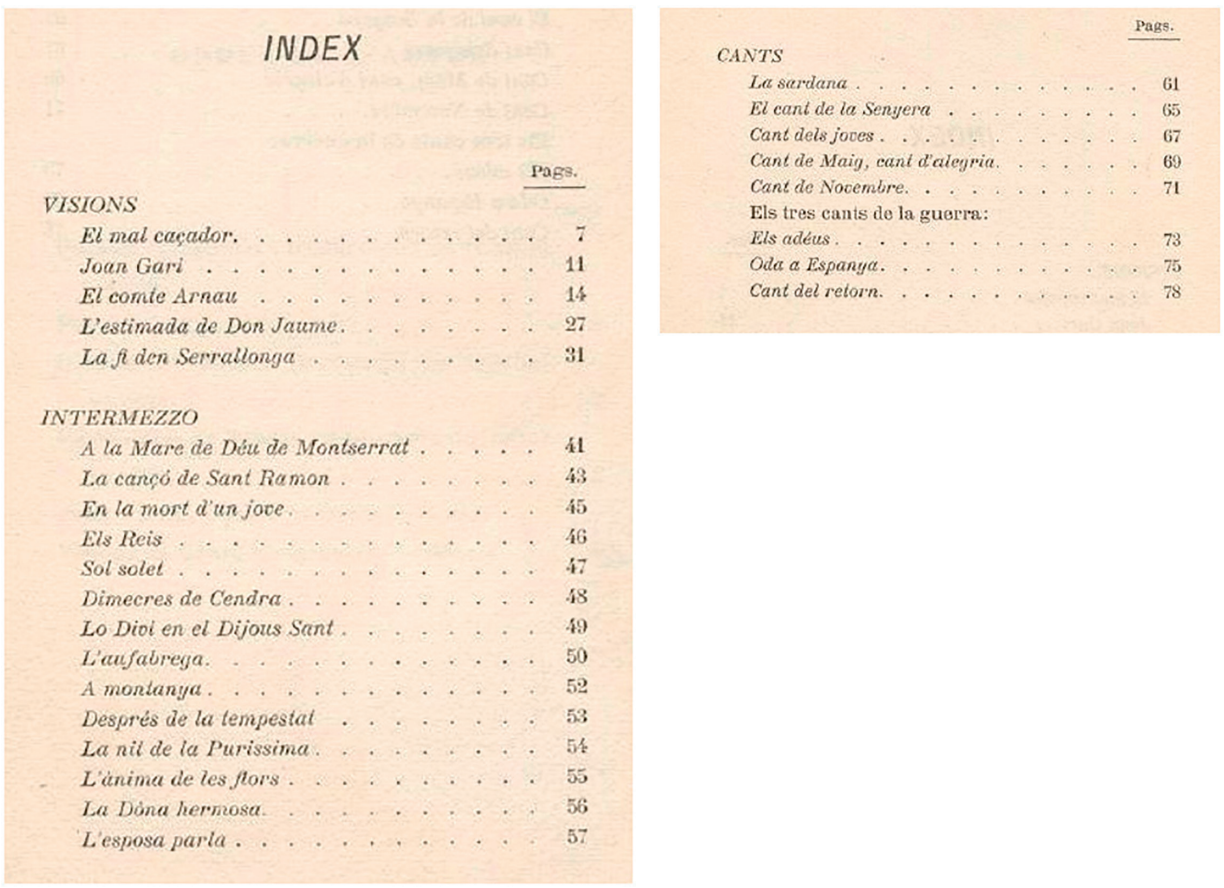
Més complex és el que fa tipogràficament el volum Enllà amb el grup de poemes Les muntanyes, que inclou un primer poema homònim, un segon poema («Retorn») dividit en quatre parts numerades, i dos poemes més sense divisions internes («Represa» $\mathrm{i}$ «Glosa»). El títol «Les muntanyes» apareix amb la tipografia pròpia de títol de poema, i va seguit efectivament pel poema que coneixem amb aquest títol. A continuació, i sense començar en pàgina nova, s'hi inclouren «Retorn», «Represa» $\mathrm{i}$ «Glosa» amb el títol en un cos de lletra inferior, procediment que es repeteix a l'índex. Això podria fer pensar que «Retorn», «Represa» $\mathrm{i}$ «Glosa» són parts del poema «Les muntanyes», però una simple lectura dels textos ho desmenteix de seguida. També les circumstàncies de redacció i difusió són ben diferents. Són, doncs, clarament quatre poemes independents, però quan Maragall els aplega dins el llibre Enllà els presenta amb aquesta disposició tipogràfica tan insòlita perquè els títols d'aquests poemes dialoguen entre ells: «Les muntanyes» ens ofereix el marc i ens anuncia el tema; després ve el «Retorn» (retorn a les muntanyes, òbviament), la «Represa» (represa del tema de les muntanyes) i la «Glosa» (glosa de la cançó gascona que parla de les muntanyes). De fet, retorn, represa i glosa són, en certa mesura, termes sinònims: tots tres subratllen la insistència en un tema donat. Són, per dir-ho amb Genette, títols remàtics, no pas temàtics, en la mesura que ens parlen més del gènere que de la cosa (del fet que reprenen i no d'allò que reprenen). És a dir: «Les muntanyes» és l'únic títol temàtic dels quatre; «Retorn», «Represa» $\mathrm{i}$ «Glosa» són títols remàtics que remeten al primer. I és aquest joc sofisticat establert entre «Les muntanyes», «Retorn», «Represa» $\mathrm{i}$ «Glosa» el que justifica que la tipografia del cos del llibre i la de l'índex els presenti com a grup de poemes diferenciat dels que venen a continuació, que són també de temàtica muntanyenca però aliens a aquest joc de represes: «Del Montseny» $\mathrm{i}$ «Del Montjuïc». Maragall hauria pogut aplegar tots els poemes de tema muntanyenc en una secció diferenciada de «Vistes la mar», que haurien pogut constituir una altra secció que s'hi contraposés, però aleshores s'hauria diluït el sofisticat joc de miralls del grup de poemes Les muntanyes.

\section{VII.- L’ABSÈNCIA D'ALTRES INSTÀNCIES PARATEXTUALS}

Cal assenyalar també la sobrietat amb què Maragall adreça la seva obra al lector. Els seus llibres disposen, com hem vist, de títol, en ocasions de subtítol, de títols de seccions de poemes, de títols de grups de poemes, de títols de poemes, de numeracions per marcar divisions internes i de taula de continguts al final del llibre, a més dels obvis paratextos editorials (nom de l'autor, nom de l'editor, data, numeració de pàgines, llistat d'altres títols de l'autor...). Però cap dels llibres de Maragall no té dedicatòries, ni pròlegs autorials (tret del breu pròleg a Les disperses, adreçat als editors), ni pròlegs al-lògrafs (tret del pròleg de Lluís Via també a Les disperses, reproduït dins Maragall 2020: 415-438), ni notes de cap mena. Maragall confia la seva obra al lector sense voluntat d'aclarir-li res, sense voler orientar la lectura amb declaracions sobre aquella obra. És, doncs, una actitud de confiança en la pròpia paraula poètica i de confiança en el paper del lector a l'hora d'interpretar-la. És significatiu que les dues excepcions que hem assenyalat (un pròleg autorial i un pròleg al-lògraf) pertanyin totes dues a Les disperses, el 
llibre - ho hem assenyalat reiteradament- més singular de tots els llibres poètics de Maragall pel fet d'haver sigut preparat a iniciativa aliena.

Tampoc no és possible trobar un gran nombre d'epitextos públics (Genette 1987: 346): Maragall reflexiona a fons sobre el fet d'escriure i elabora una coneguda proposta teòrica en l'àmbit de la poètica (Quintana 1996; Pla i Arxé 1998 i 2012; Moreta: 215-237 i 315-351), però rarament escriu específicament sobre els seus llibres o els seus poemes. Els epitextos associats als seus llibres de poesia i als seus poemes són fonamentalment privats: són les cartes als amics les que ens proporcionen informació de primera mà sobre el procés de composició d'alguns dels seus poemes, sobre el procés de confecció dels seus llibres o sobre les seves intencions en escriure alguns dels seus textos. De vegades, a més, la motivació d'aquestes declaracions és simplement la de donar resposta a comentaris formulats pels seus amics, com passa en el cas de les famoses declaracions sobre El comte l'Arnau fetes a Joan Pérez Jorba i a Carles Rahola en cartes del 14 d'abril de 1911 i del 6 de juliol de 1911 respectivament. En general, Maragall tendeix a deixar que se'l llegeixi com es vulgui, com diu explícitament a Lluís Lluís el 20 de febrer de 1911 (Maragall 1961: 914):

En la meva poesia no hi ha res de pensat: no faig cap vers que no m'acudi ja fet i format en el calor de la pura emoció. Sols després de fet, mirant-me'l de fora estant, com si l'hagués fet un altre, puc dir: Això es pot prendre en tal o qual sentit filosòfic, ètic, moral, \& \&. Aixís no m'estranya que després algú hi trobi encara sentits que jo ni en aquell moment posterior he endevinat. I si em diuen per exemple: «Això és spinozià», respondré: «Potser sí; vostè dirà».

\section{VIII.- QUADRE-RESUM}

Ofereixo a continuació un petit quadre que permet un còmput àgil del nombre de poemes que contenen els llibres de Maragall i de la seva distribució en seccions i grups:

\begin{tabular}{|l|c|c|c|c|c|c|c|}
\hline \multicolumn{1}{|c|}{ Llibre } & $\begin{array}{c}\text { Nombre } \\
\text { de } \\
\text { seccions }\end{array}$ & $\begin{array}{c}\text { Nombre } \\
\text { de grups } \\
\text { de poemes } \\
\text { numerats }\end{array}$ & $\begin{array}{c}\text { Nombre } \\
\text { de grups } \\
\text { de poemes } \\
\text { no } \\
\text { numerats }\end{array}$ & $\begin{array}{c}\text { Nombre } \\
\text { de } \\
\text { poemes } \\
\text { integrats } \\
\text { en } \\
\text { seccions }\end{array}$ & $\begin{array}{c}\text { Nombre } \\
\text { de } \\
\text { poemes } \\
\text { fora de } \\
\text { secció }\end{array}$ & $\begin{array}{c}\text { Nombre } \\
\text { de } \\
\text { poemes } \\
\text { integrats } \\
\text { en grups }\end{array}$ & $\begin{array}{c}\text { Nombre } \\
\text { total de } \\
\text { poemes }\end{array}$ \\
\hline Poesies & 5 & 1 & 0 & 21 & 0 & 6 & 21 \\
\hline $\begin{array}{l}\text { Visions \& } \\
\text { Cants }\end{array}$ & 3 & 0 & 1 & 27 & 0 & 3 & 27 \\
\hline Les disperses & 0 & 0 & 0 & 0 & 20 & 0 & 20 \\
\hline Enllà & 1 & 0 & 1 & 2 & 8 & 4 & 10 \\
\hline Seqüiències & 4 & 1 & 0 & 17 & 0 & 7 & 17 \\
\hline TOTAL & 13 & 2 & 2 & 67 & 28 & 20 & 95 \\
\hline
\end{tabular}




\section{IX.- CONCLUSIONS}

La caricatura sobre Maragall difosa des de posicions hostils a la poètica maragalliana ens el presenta com un autor indolent, poc acurat, poc professional, que escriu i publica sense mètode i sense rigor, tal com surt. Les declaracions explícites de Maragall a favor d'una poètica que prioritza la inspiració i el fragmentarisme i que rebutja el mètode, la construcció, la refosa i l'embelliment dels textos han reforçat a fons aquesta caricatura.

Tanmateix, l'estudi del procés de confecció dels seus llibres i de l'organització dels textos dins els volums fa aflorar una visió molt diferent de la del vulgar espontaneisme que els detractors de Maragall li atribueixen. Maragall construeix els seus llibres amb plena consciència i amb un alt sentit de la responsabilitat. Tots els seus llibres poètics són miscel-lanis, però no són aplecs indiscriminats. Maragall pensa a fons els títols i subtítols, els materials que inclou i els que descarta, l'organització dels textos en seccions i grups de poemes, i controla amb força detall els recursos tipogràfics i les inscripcions paratextuals emprats per visibilitzar aquesta organització textual. Certament, no és del tot sistemàtic, i la diversitat de criteris tipogràfics d'un llibre a l'altre reforça aquesta sensació d'asistematicitat, però seria un error concloure que hi ha indolència o falta de professionalitat en la manera d'aplegar els textos i organitzar-los. Al contrari: podem constatar que hi ha una organització dels textos pensada a fons i, en alguns casos, molt sofisticada. Es una organització amb sentit que contribueix a fer llegir els poemes i els llibres d'una determinada manera, subratllant les continuïtats temàtiques que es produeixen d'un volum a l'altre. Per això, no és acceptable publicar l'obra poètica completa de Maragall sense respectar la disposició dels textos decidida per Maragall, com s'ha fet en algunes edicions pòstumes (Casals 1991), ja que fent-ho s'invisibilitza una organització textual que forma part de les decisions que pren l'autor a l'hora de presentar la seva obra al públic.

Unes paraules de Joan Ferraté (1976: 21) a propòsit de Carner ens poden servir per comprendre, mutatis mutandis, la manera de treballar de Maragall:

L'aplegament dels poemes de Carner a Poesia, la seva distribució en seccions i l'ordenació d'aquestes seccions responen, doncs, a un pla unitari que pot ser identificat amb una precisió suficient. [...] L'ordre dels poemes dins de cada secció, [...] el lector pot confiar que respon també a una certa idea deliberada de la ment de l'autor i no pas a qualsevol atzar fortuït. Creure el contrari fóra, si més no, una greu impertinència contra Carner, que no sembla pas que hagi estat persona inclinada a presentar-se, ell o res seu, davant del públic com deixat de la mà de Déu.

Com en el cas de Carner, els textos de Maragall es presenten al lector organitzats en els seus llibres d'acord amb «una certa idea deliberada en la ment de 
l'autor» i no pas per cap «atzar fortuït». Com Carner, Maragall no va voler presentar mai res seu, davant el públic, «com deixat de la mà de Déu». ${ }^{4}$

${ }^{4}$ Arribat aquí, vull expressar el meu agraïment a Jordi Cornudella (Edicions 62), Lluís Quintana Trias (UAB) i Francesco Ardolino (UB) per l'atentíssima lectura que han fet de diverses versions d'aquest article. La responsabilitat sobre els desencerts del text és exclusivament meva. 


\section{Annex}

Taula de continguts dels cinc llibres de poesia de Maragall

\section{Poesies:}

PRÒLEG

«Oda infinita»

CLAROR

«Les minves del gener»

«Ella parla»

«Enviant flors»

«Festeig vora la mar Cantàbrica»

I

II

III

IV

V Adeu

«Donant les joies»

«Nuvial»

«Conjugal»

«Paternal»

PIRENENQUES

[Pirenenques]

I «A dalt del Pirineu...»

II «Tot està immoble dalt del Pirineu...»

III «Ben ajagut a terra, com me plau...»

IV «Els núvols blancs: flonjos van caient...»

V «Acabada la pluja de la tarda...»

VI «Plau-me, el bastó del caminant al puny...»

«a vaca cega»

«Goigs a la Verge de Núria»

TRÍPTIC DE L'ANY

«Quaresma»

I

II 
III

IV

V

«Corpus»

I

II

III

IV Unes flors que s'esfullen

«Nadal»

EPÍLEG

«Excelsior»

\section{Visions \& Cants:}

VISIONS

«El mal caçador»

«Joan Garí»

I

II

III

IV

«El comte Arnau»

I

II

III

IV

V

VI

VII

VIII

IX

X

«L'estimada de Don Jaume»

I

II

III

IV

$\mathrm{V}$

«La fi d'en Serrallonga» 
INTERMEZZO

«A la Mare de Déu de Montserrat»

«La cançó de sant Ramon cantada per una russa»

«En la mort d'un jove»

«Els Reis»

«Sol, solet...»

«Dimecres de Cendra»

«Lo Diví en el Dijous Sant»

«L'aufàbrega»

«A muntanya»

«Després de la tempestat»

«La nit de la Puríssima»

«L'ànima de les flors»

«La Dona hermosa»

«L'esposa parla»

CANTS

«La sardana»

I

II

III

IV

«El cant de la Senyera»

«Cant dels joves»

«Cant de maig, cant d'alegria»

«Cant de novembre»

Els tres cants de la guerra

«Els adeus»

«Oda a Espanya»

«Cant del retorn»

\section{Les disperses:}

Als amics de Joventut

LES DISPERSES

«Dins sa cambra»

«L'hort»

«ugant»

«Diumenge»

«Romanza sens paraules»

«A un amic»

«Diades d'amor» 
I
II
III
IV
V

«Davant del temporal»

I

II

III

«Haidé»

«Matinal»

«Pirenenca»

«Per la boira»

«Hospitalàries»

«L'ametller»

«Oració a santa Llúcia»

«Els núvols de Nadal»

«La balada del bes»

«La missatgera més segura»

«Soleiada»

«Les roses franques»

TRADUCCIONS DE GOETHE

\section{Enllà:}

«Els ametllers»

«Vistes al mar»

I

II

III

IV

V

[Les muntanyes]

«Les muntanyes»

«Retorn»

I

II

III

IV

V 
«Represa»

«Glosa»

«Del Montseny»

«Del Montjuïc (en la tomba nova d'en Verdaguer)»

L'ÀNIMA

«L'ànima»

I

II La cançó del comte l'Arnau

III

IV

$\mathrm{V}$

VI

VII

«Escòlium»

\section{Seqüiències:}

SEGUIT DE LES VISTES AL MAR

[Seguit de les vistes al mar]

I «La ginesta altra vegada...»

II «La mar estava alegre aquest migdia...»

III «Flameja al sol ponent l'estol de veles...»

IV «El pi d'Estrac»

$\mathrm{V}$ «Allà en les llunyanies de la mar»

VI «Comença la tardor damunt dels camps...»

VII «Tot plegat mar i cel s'han ennegrit...»

«La fageda d'en Jordà»

REPRESA D'HAIDÉ I ALTRES

«Represa d'Haidé»

«Havent sentit Beethoven per Miecio Horszowski infant»

«La sirena (fragment)»

«Primer dol»

«En una casa nova»

«Fi d'any»

ODA NOVA A BARCELONA

«Oda nova a Barcelona»

LA FI DEL COMTE L'ARNAU I CANT ESPIRITUAL

«La fi del comte l'Arnau»

«Cant espiritual» 


\section{BIBLIOGRAFIA}

Abrams, S. (2010) Llegir Maragall, ara, Barcelona, Proa.

Casals, G. (1991) «Notes sobre les edicions pòstumes de la poesia de Joan Maragall», Els Marges, núm. 43, pp. 77-87.

Ferraté, J. (1976) «"Poesia”, de Josep Carner: Ressenya i vindicació», Els Marges, núm. 8, setembre, pp. 15-32.

Genette, G. (1987) Seuils, París, Seuil.

Maragall, J. (1909) Tría. Llibre de lectures selectes, en prosa y vers, pera els nois y noyes de les escoles y col-legis de Catalunya, Girona, Dalmau Carles.

Maragall, J. (1912) Obres completes, Poesies I, Barcelona, Gustau Gili.

Maragall, J. (1947) Obres completes, Barcelona, Selecta.

Maragall, J. (1960) Obres completes, vol. I, Obra catalana, Barcelona, Selecta.

Maragall, J. (1961) Obres completes, vol. II, Obra castellana, Barcelona, Selecta.

Maragall, J. (1986) Poesia completa, edició a cura d'Enric Bou, Barcelona, Empúries.

Maragall, J. (1995) El comte Arnau, estudis introductoris de Josep Romeu i Figueras, Arthur Terry i Joan-Lluís Marfany, Barcelona, Edicions 62.

Maragall, J. (1998) Poesia. Edició crítica, a cura de Glòria Casals, Barcelona, La Magrana.

Maragall, J. (2010a) Poesia completa, edició de Glòria Casals i Lluís Quintana, Barcelona, Edicions 62.

Maragall, J. (2010b) El comte Arnau, estudi preliminar, propostes de treball i material complementari a cura de Lluís Quintana, edició a cura de Glòria Casals, Barcelona, Educaula.

Maragall, J. (2020) Obres completes, vol. I, Poesia i teatre, edició crítica d'Ignasi Moreta i Lluís Quintana Trias, Barcelona, Edicions 62.

Moreta, I. (2010) No et facis posar cendra. Pensament i religió en Joan Maragall, Barcelona, Fragmenta.

Ors, E. (2001) Glosari 1908-1909, edició i presentació de Xavier Pla amb la col-laboració en l'anotació de Xavier Albertí, Barcelona, Quaderns Crema.

Pla i Arxé, R. (1998) La poètica de Joan Maragall, Barcelona, Claret.

Pla i Arxé, R. (2012) La poètica de Joan Maragall, dins P. Lluís Font (coord.), Les idees religioses de Joan Maragall, Barcelona, Editorial Cruilla / Fundació Joan Maragall, p. 33-89.

Quintana Trias, L. (1996) La veu misteriosa. La teoria literària de Joan Maragall, Barcelona, Publicacions de l'Abadia de Montserrat.

Terry, A. (1964) «L'epistolari de Joan Maragall i Felip Pedrell 1899-1911», Estudis Romànics, VII, 1959-1960, pp. 11-62. 